\title{
Documentación conventual de procedencia madrileña en el Archivo Diocesano de Mérida-Badajoz
}

\author{
Guadalupe PÉREZ ORTIZ \\ Biblioteca Seminario San Atón de Badajoz \\ mgperort@alcazaba.unex.es \\ Agustín Vivas MORENO \\ Universidad de Extremadura \\ avivas@alcazaba.unex.es
}

Recibido: Febrero 2013

Aceptado: Mayo 2013

Resumen: La finalidad del presente artículo es el análisis de los documentos conventuales custodiados en el Archivo Diocesano de Mérida-Badajoz que reflejan en su data tópica la población de Madrid. Para ello, tras la exposición de unas necesarias notas históricas sobre el archivo, realizaremos un análisis de la documentación desde múltiples perspectivas: su condición de manuscrito o impreso, cronología, idioma, entidades y contenidos. Tras este análisis abordaremos el motivo por el cual existe en este archivo extremeño un foco importante de documentos conventuales con dicha procedencia. El estudio concluye con el catálogo documental.

Palabras clave: Archivo Diocesano de Mérida-Badajoz; Documentación conventual; Madrid.

\section{Conventual documentation of origin of Madrid in the Diocesan File of Merida - Badajoz}

\begin{abstract}
The purpose of this article is the analysis of the conventual documents guarded in the Archivo Diocesano de Mérida-Badajoz, that they reflect in his hackneyed byline the population of Madrid. For it, after the exhibition of a few historical notes of our file, we will realize an analysis of the documentation from multiple perspectives: manuscript or form, chronology, language, entities and contents. After this analysis we will approach the motive for which there exists in this Extremadura file an important area of conventual documents with the above mentioned origin. The study concludes with the documentary catalogue.
\end{abstract}

Keywords: Archivo Diocesano de Mérida-Badajoz; Conventual documentation; Madrid. 


\section{INTRODUCCIÓN}

En líneas generales, los archivos diocesanos son aquellos que custodian la documentación generada por el obispo y su curia en el desarrollo de las múltiples actividades que les han sido asignadas. Su datación se sitúa hacia el siglo XVI, muy estrechamente ligada a las cláusulas emanadas del Concilio de Trento (15451563), en las que se dispone la observancia de residencia obispal obligatoria. A pesar de su tardío nacimiento y de los avatares a los que tuvieron que enfrentarse hasta su consolidación, los archivos episcopales han destacado por su volumen y riqueza documental.

El Archivo Diocesano de Mérida-Badajoz es por tanto el custodio de la documentación generada por el obispo en la administración de la Diócesis pacense. Como tal, y en base a las múltiples comunicaciones que mantiene con las distintas entidades de su jurisdicción eclesiástica genera documentación muy variada. Una de estas entidades son las conventualidades extremeñas, que han dado lugar a una interesante y abundante producción documental que hace referencia a multitud de conventos, procedencias, topografías y contenidos. Dentro de esta documentación hemos seleccionado la que presenta procedencia madrileña, dado que aunque su volumen no es excesivamente abundante expone documentos de gran relevancia, no sólo por sus contenidos si no por las entidades que las han producido.

\section{EL ARCHIVO DIOCESANO DE MÉRIDA-BADAJOZ: APROXIMACIÓN HISTÓRICA}

En líneas generales debemos decir que son muy escasos los datos que conocemos sobre este archivo. Tras la consulta de algunos estudios sobre la Diócesis de Badajoz ${ }^{1}$ podemos afirmar que su nacimiento se sitúa coetáneo a la reestructuración del Obispado, hacia el 1255. Si tenemos en cuenta que fueron las cláusulas emanadas del Concilio de Trento (1545-1563) las que determinaron la obligatoriedad de crear archivos diocesanos, debemos afirmar que en el Obispado Pacense existía un archivo previo, aunque desconocemos datos fiables sobre el mismo.

Conocemos de la mano del historiador Alberto González Rodríguez que se situaba en el interior del Palacio Episcopal. Su ubicación originaria es desconocida, alojándose desde los momentos iniciales, de los que tenemos constancia, en el llamado "Almacén del Rey" que en 1380 fue consolidado como sede episcopal tras ser donado a la Iglesia por el rey Juan I de Castilla a don

\footnotetext{
${ }^{1}$ Aldea Vaquero; Marín Martínez; Vives Gatell, 1972-1987:170-171; López López, 2000; Sarmiento Pérez, 2005; Solano de Figueroa, 1929-1932; Solar y Taboada, 1945; Suárez de Figueroa, 1976.
} 
Fernando Suárez de Figueroa ${ }^{2}$. Sabemos que el Episcopado se mantuvo allí hasta 1705, fecha en la que el obispo Marín de Rodezno decidió su traslado debido a la explosión de un polvorín cercano ${ }^{3}$. Esta situación hace que el Obispado sea trasladado a un edificio que le había sido donado, situado en la calle que unía el Campo de San Francisco con el de San Juan. En estas dependencias se producen cambios importantes. El primero de ellos viene de la mano del obispo don Francisco Valero y Losa, que en 1707 nombró como archivero a don Antonio Gómez Fabra. La segunda de las medidas fue efectuada por el obispo don Pedro Francisco de Levanto y Vibando, y supuso el traslado del archivo a la planta superior del edificio en busca de mejores condiciones ${ }^{4}$.

Ya en el siglo XIX, la Revolución Francesa fue un hecho de terribles consecuencias para la Iglesia española y su patrimonio. El Obispado de Badajoz no se vio libre de ataques y, en particular, su archivo fue asaltado suponiendo la pérdida de gran número de expedientes ${ }^{5}$.

En el siglo XX, la Guerra Civil Española (1936-1939) no supuso un motivo de pérdidas documentales importantes, puesto que el mayor deterioro que sufrieron los documentos fue por el caos que se produjo en el intento de salvaguardarlos. En la segunda mitad del siglo XX, el Archivo sufre cuatro traslados. Más tarde, el Obispado adquiere la Casa del Cordón (1995), y traslada allí sus dependencias ${ }^{6}$.

El siglo XXI comienza como una etapa de cambios en la Archidiócesis de Mérida-Badajoz. En el 2003 es nombrado arzobispo don Santiago García Aracil. $\mathrm{Su}$ potencial interés por salvaguardar el patrimonio eclesiástico y ponerlo a disposición de cuantos lo puedan necesitar, le ha llevado a la unificación de los fondos diocesano y catedralicio, con la perspectiva de que los archivos de la Archidiócesis queden reunidos. En la actualidad, se trabaja incesantemente en el archivo realizando labores de inventariado, así como de descripción de series documentales, expedientes y documentos.

\section{EL ARCHIVO DIOCESANO DE MÉRIDA-BADAJOZ: CUSTODIO DE LA DOCUMENTACIÓN CONVENTUAL}

Analizada, siquiera brevemente, la historia del Archivo Diocesano de MéridaBadajoz nos disponemos ahora a acercar al lector la documentación conventual para que pueda conocer, al menos en líneas generales, las características más destacadas de la misma.

\footnotetext{
${ }^{2}$ González Rodríguez, 1999: 189-190.

${ }^{3}$ Asociación de Archiveros de la Iglesia, 2000: 37.

${ }^{4}$ Ibidem, p. 38.

${ }^{5}$ Aldea Vaquero; Marín Martínez; Vives Gatell, 1972-1987: 262-263.

${ }^{6}$ Montes, 2002: contraportada.
} 
La documentación sobre conventos conservada en el fondo antiguo del Archivo Diocesano de Mérida-Badajoz se encuentra almacenada en legajos. En total, se distribuye entre 146, de los cuales 34 son procedentes del archivo del "Obispado," puesto que recogen documentación de localidades que, en el ámbito eclesiástico, han dependido del Obispado de Badajoz a lo largo de los tiempos. Por su parte, los 112 legajos restantes se ubican en el archivo del "Priorato de San Marcos de León" y son los que custodian la documentación de localidades que pertenecían, hasta su desaparición en 1873, al Priorato que lleva su nombre.

Respecto a su cronología, la documentación relativa a la temática conventual, en su fondo antiguo, se distribuye desde los siglos XVI al XIX, en los que encontramos el primer y el último documento. La tabla que a continuación se presenta permite conocer la distribución de la documentación conventual diocesana por siglos de emisión.

Tabla 1. Distribución cronológica de los documentos conventuales. Elaboración propia

\begin{tabular}{|l|c|c|c|}
\multicolumn{4}{|c|}{$\begin{array}{c}\text { DISTRIBUCIÓN CRONOLÓGICA DE LOS DOCUMENTOS } \\
\text { CONVENTUALES }\end{array}$} \\
\hline SIGLOS & DOC & $\%$ & \% ACUMULADO \\
\hline Siglo XVI & 11 & 0,73 & 0,73 \\
\hline Siglo XVII & 248 & 16,58 & 17,31 \\
\hline Siglo XVIII & 350 & 23,44 & 40,75 \\
\hline Siglo XIX & 861 & 57,59 & 97,47 \\
\hline Siglo XX & 1 & 0,06 & 97,8 \\
\hline Sd. & 24 & 1,6 & 100 \\
\hline Total & 1495 & 100 & 100 \\
\hline
\end{tabular}

Respecto a la lengua en la que se ha producido la documentación conventual señalar que de las 1495 agrupaciones documentales que configuran el fondo conventual, 1321 se presentan íntegramente en lengua castellana, lo cual supone un porcentaje del $88,36 \%$ respecto al total. En segundo lugar, aparecen los expedientes que combinan castellano-latín con un total de 174, que suponen el 11,64\%.

El estudio de la procedencia de los documentos conventuales, nos permitirá el conocimiento en profundidad de las entidades o particulares que han producido la documentación conventual que fue transferida posteriormente al archivo diocesano. La tabla que a continuación presentamos da prueba de ello. 
Tabla 2. Procedencias documentales. Elaboración propia

\begin{tabular}{|c|c|c|}
\hline \multicolumn{2}{|c|}{ PROCEDENCIAS DOCUMENTALES } \\
\hline \multicolumn{2}{|c|}{ PROCEDENCIAS } & ENTIDADES \\
\hline & CONVENTUAL & Conventos \\
\hline ECLESIÁSTICA & & Obispado Pacense \\
\hline & SECULAR & Nunciaturas \\
& & Apostólicas \\
\hline & & Roma (Sede \\
& & Apostólica) \\
\hline & & Ministerio de Gracia \\
& & y Justicia \\
\hline
\end{tabular}

Como podemos observar hemos segmentado las procedencias documentales en dos grandes grupos: en el primero de ellos, se situará toda aquella documentación de procedencia puramente eclesiástica. Ésta se subdivide en conventual (documentación originada de forma exclusiva por entidades conventuales) y secular (documentación producida por otras entidades del ámbito eclesiástico). En segundo lugar, hemos identificado la procedencia civil, que dará cabida a toda aquella documentación emanada por entidades laicas, en oposición a las procedentes de la Iglesia.

Para finalizar con este apartado, señalar que se conservan en el archivo 1495 agrupaciones documentales sobre conventos, distribuidas entre 85 entidades adscritas a 7 órdenes religiosas: San Agustín, San Francisco, Santo Domingo, Carmelo Descalzo, San Jerónimo, Santísima Trinidad y Compañía de Jesús.

Tabla 3. Procedencia y documentación conventual. Elaboración propia

\begin{tabular}{|c|c|c|}
\hline \multicolumn{3}{|c|}{ PROCEDENCIA Y DOCUMENTACIÓN CONVENTUAL } \\
\hline PROCEDENCIA & DOC & $\%$ \\
\hline Orden Franciscana & 673 & 56,08 \\
\hline Orden Agustina & 266 & 22,16 \\
\hline Orden Carmelita & 101 & 8,41 \\
\hline Orden de la Santísima Trinidad & 60 & 5 \\
\hline Orden Jerónima & 50 & 4,16 \\
\hline Orden Dominica & 44 & 3,66 \\
\hline Compañía de Jesús & 6 & 0,5 \\
\hline Total & 1495 & 100 \\
\hline
\end{tabular}


Como se deduce de la tabla anterior es la orden de San Francisco la que aporta el mayor volumen documental al fondo conventual del Archivo Diocesano de Mérida-Badajoz. Por su parte, en el extremo contrarío se sitúa la Compañía de Jesús con tan sólo 6 documentos. Esta situación condicionará futuros estudios dado que a medida que la documentación sea más voluminosa nos permitirá desarrollar análisis más profundos y exhaustivos de la misma y extrapolar conclusiones a la propia orden emisora.

Conocidas, al menos de forma general, la historia y el devenir del Archivo Diocesano de Mérida-Badajoz y las características principales de su documentación conventual seguiremos avanzando en nuestro análisis y veremos ahora las causas principales por las que en el fondo conventual del Archivo Diocesano de Mérida-Badajoz (ADME-BA) aparece documentación en cuya data tópica, por unos u otros motivos, se registra la ciudad de Madrid.

\section{JUSTIFICACIÓN DE LA PROCEDENCIA MADRILEÑA EN LA DOCUMENTACIÓN CONVENTUAL DEL ARCHIVO DIOCESANO DE MÉRIDA-BADAJOZ}

Proponemos ahora, como decimos, justificar cuáles son los motivos principales que llevan a la aparición de la ciudad de Madrid, en la data tópica, de un número significativo de documentos conventuales custodiados en el fondo antiguo del Archivo Diocesano de Mérida-Badajoz. Es importante precisar, antes de comenzar este apartado y para evitar posibles equívocos, que en todos los casos en los que aparece en la documentación conventual la población de Madrid se refiere a Madrid ciudad y en ninguno de ellos hace referencia a la provincia de Madrid o a la diócesis madrileña.

Es un hecho que se repite hasta en 190 ocasiones del total de agrupaciones documentales sobre conventos que se custodian en este archivo, suponiendo un 14 $\%$. Porcentaje significativo, que no podemos obviar dado que supone que Madrid es la población fuera de los límites extremeños que aparece en un mayor número de ocasiones en la documentación conventual sita en esta entidad. Por ello, hemos considerado analizarla en mayor profundidad.

Tras el análisis de la documentación podemos observar que la razón fundamental por la que aparece la población madrileña junto con otras poblaciones extremeñas -en ningún caso aparece de forma exclusiva- en la data tópica de nuestros documentos conventuales se debe a la ubicación de dos entidades que, fundamentalmente en el primer tercio del siglo XIX, fueron decisivas para el desarrollo de las conventualidades españolas condicionándolas fuertemente, como da prueba de ello la historia de la Iglesia española y la documentación analizada. Dichas entidades son: la Nunciatura Apostólica Española y el Ministerio de Gracia y Justicia.

Veamos brevemente en qué afectaron a las conventualidades extremeñas cada 
una de estas entidades, así como los contenidos que generaron cada una de ellas tras la ejecución de sus variadas disposiciones:

La Nunciatura Apostólica es un organismo eclesiástico de representación. En España, con carácter permanente, existe una Nunciatura Apostólica desde el año 1528. El representante de este organismo es el Nuncio. Según el diccionario de la Real Academia Española el Nuncio es: representante diplomático del Papa, que ejerce además, como legado, ciertas facultades pontificias. Además de esta función de representación, los Nuncios, tienen derecho de precedencia eclesiástica en su territorio. También pueden actuar como Delegados Apostólicos por encargo del Papa. El cargo de Nuncio, siempre debe recaer en el Decanato del Cuerpo Diplomático acreditado en Madrid. Además de los honores que le corresponden por su dignidad eclesiástica, deben tener los honores que se le dan a cualquier otro embajador de cualquier otro país extranjero.

La población madrileña aparece, por tanto, como consecuencia directa de que desde mediados del siglo XVI la Nunciatura Apostólica española se ubicara en la ciudad de Madrid. Ahora toca discernir en qué casos o, mejor dicho, en qué tipo de contenidos aparece presente la ciudad de Madrid como sede de esta entidad eclesiástica. Tras el análisis documental realizado podemos señalar que más del 90 $\%$ de los documentos objeto de estudio reflejan esta situación, es decir, son emitidos o recibidos por la Nunciatura Apostólica española. Veamos estos contenidos:

- Concesión de pensión alimenticia a conventos;

- Cuentas de reparación;

- Elecciones conventuales;

- Estado ruinoso de entidades conventuales;

- Libros prohibidos;

- Patronazgo;

- Petición de religiosas para seguir habitando un convento;

- Pleitos;

- Privilegios de diezmos;

- Salidas temporales de conventos;

- Secularizaciones (temporales y perpetuas);

- Toma de hábito y profesión perpetua;

- Ventas propiedades conventualidad.

Como pueden observar en la lista de contenidos expuestos, el papel fundamental que desempeña la Nunciatura Eclesiástica española en relación a estos procesos es el de entidad validadora, es decir, se trata del órgano eclesiástico que se encarga de conceder o denegar la ejecución de trámites, todos ellos de relevancia para el funcionamiento de los conventos, que previamente han sido comunicados al 
Obispado de Badajoz por las entidades conventuales: salidas, pensiones, secularizaciones, tomas de hábitos, ventas, etc. Sin la aprobación de la Nunciatura Apostólica ninguno de estos procesos tendría validez eclesiástica y por tanto, no podrían ser llevados a la práctica. De entre los contenidos expuestos, por su mayor volumen y significación, debemos destacar la función que la Nunciatura Apostólica española cumple en las secularizaciones, ya sean temporales o perpetuas, dado que es la encargada de validarlas, después de la consiguiente petición del religioso/a a su orden y de los trámites oportunos que han debido ser ejecutados en el obispado. El primer tercio del siglo XIX nos muestra la intervención de esta entidad hasta en 141 procesos secularizadores en nuestra provincia.

Dejando a un lado la entidad eclesiástica, nos situaremos ahora en la parte civil, esto es, en el Ministerio de Gracia y Justicia, cuya ubicación no era otra que la ciudad madrileña. Aunque su volumen documental, según los documentos analizados, es notoriamente inferior, no es menos cierto, la intensa relevancia de los procesos en los que participó y como consecuencia de ello, la importancia de los contenidos que generó a lo largo de la historia. Prueba de ello, son los documentos que podemos encontrar en nuestro archivo. Veamos estos contenidos:

- Carta de privilegio, por la que su majestad el rey Carlos II concede al convento de Carmelitas Descalzas de Talavera la Real 15300 maravedíes de un juro en Jaén;

- Ley de desalojo conventual de 25 de octubre de 1820 ;

- Real cédula de 3 de mayo de 1816 por la que se restablece la Compañía de Jesús en España;

- Real orden de 2 de mayo de 1822 pidiendo razón de los religiosos y monjes secularizados;

- Real orden de 20 de octubre de 1822 sobre traslación de varios religiosos;

- Reales Órdenes sobre conventos que deben permanecer abiertos en la provincia de Badajoz.

Como se puede observar en la lista expuesta, el papel que desempeñó el Ministerio de Gracia y Justicia en relación a los conventos españoles, muy especialmente durante el primer tercio del siglo XIX, fue fundamental para el devenir de los mismos. A través de los decretos, leyes, disposiciones, etc. que formuló, condicionó el funcionamiento y devenir de la Iglesia católica española y muy especialmente el de sus conventos. Decidió qué conventos podían permanecer abiertos y por consiguiente, aquellos que debían cerrar sus puertas porque no cumplían con el número mínimo de religiosos/as (requisito marcado desde el poder civil); participó en la distribución de los religiosos de los conventos suprimidos a otros que permanecía abiertos y condicionó la distribución de sus enseres y pertenencias, documentos, bibliotecas, etc. Éstos pasaron a ser propiedad del Estado español, muchos nunca fueron devueltos a la Iglesia y otros muchos se perdieron irremediablemente. 


\subsection{ANÁLISIS DE LA LENGUA}

En cuanto a la lengua que utilizan los documentos, en cuya topografía se refleja la ciudad de Madrid, debemos señalar que existe un claro predominio de los expedientes que alternan una parte en castellano y otra en latín, con un total de 136 agrupaciones documentales de las 190 totales. La parte latina es la proveniente de la Nunciatura Apostólica Española con sede en Madrid. Tiene un carácter oficial y generalmente es de tipo impositivo. Como es lógico, aparecen documentos en esta categoría de todas las fechas y temáticas. Por su parte, hay 49 agrupaciones documentales íntegramente en castellano, que presentan también una distribución cronológica y temática amplia. Además, aparecen 5 documentos en latín cuya fecha de datación es anterior al siglo XVII. Veamos los datos a modo de tabla y gráfica:

Tabla 4. Análisis de la lengua de producción. Elaboración propia

\begin{tabular}{|l|c|c|}
\hline \multicolumn{2}{|c|}{ ANÁLISIS LENGUA DE PRODUCCIÓN } \\
\hline & Docs. & $\%$ \\
\hline Castellano & 49 & 26 \\
\hline Latín & 5 & 2,5 \\
\hline Castellano/Latín & 136 & 71,5 \\
\hline & 190 & 100 \\
\hline
\end{tabular}

Figura 1. Análisis de la lengua de producción

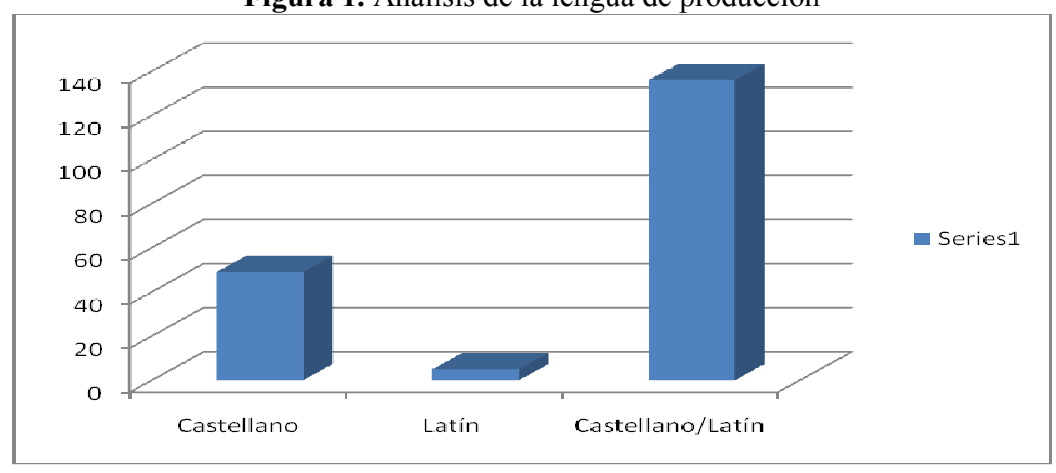

\subsection{DOCUMENTACIÓN MANUSCRITA O IMPRESA}

Si abordamos la documentación por su condición de ser manuscrita o impresa podemos afirmar que existe un total predominio de los documentos que han sido redactados a mano, 172 respecto a los 190 totales, es decir, el $90,5 \%$ de los documentos que reflejan en su topografía Madrid han sido confeccionados de forma manuscrita. Obviamente dichos documentos se corresponden con todas las 
temáticas que posteriormente desarrollaremos y presentan una distribución cronológica amplia. Encontramos 17 agrupaciones documentales que alternan una parte manuscrita y otra impresa, lo que supone un $9 \%$ del total. Y únicamente un documento íntegramente impreso, que hace referencia a la restauración de los Jesuitas en España. Veamos los datos a modo de tabla y gráfica:

Tabla 5. Documentación manuscrita/impresa. Elaboración propia

\begin{tabular}{|l|c|c|}
\hline \multicolumn{3}{|c|}{$\begin{array}{c}\text { DOCUMENTACIÓN } \\
\text { MANUSCRITA/IMPRESA }\end{array}$} \\
\hline & Docs. & $\%$ \\
\hline Manuscrita & 172 & 90,5 \\
\hline Manuscrita/Impresa & 17 & 9 \\
\hline Impresa & 1 & 0,5 \\
\hline & 190 & 100 \\
\hline
\end{tabular}

Figura 2. Documentación manuscrita/impresa

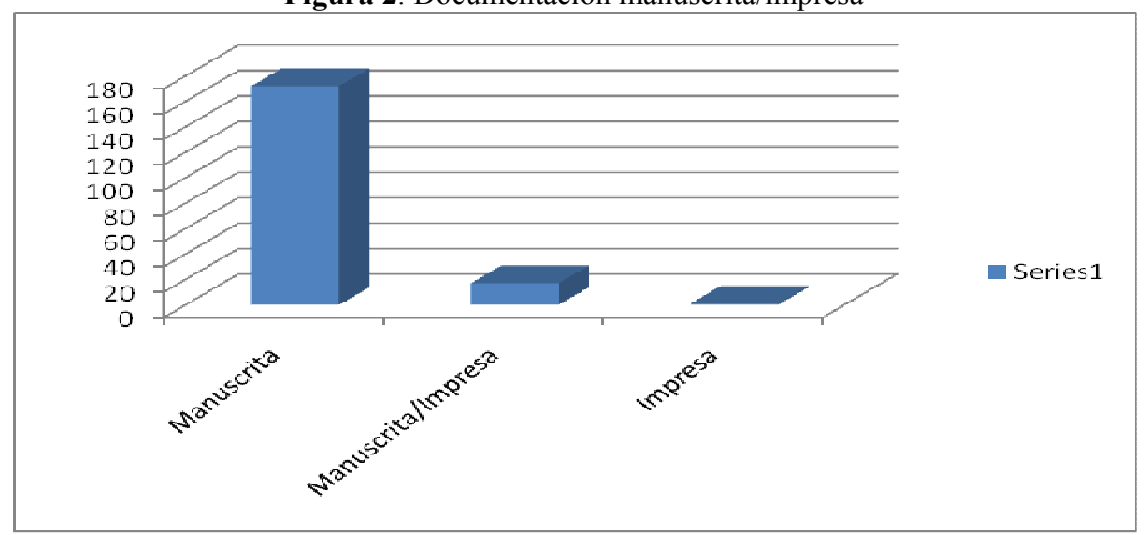

\subsection{ANÁLISIS CRONOLÓGICO}

En lo referente al análisis cronológico, la documentación se desarrolla entre los siglos XVI-XIX. Sin embargo, su distribución no es homogénea siendo más abundante en fechas más cercanas a las actuales y más escasa si nos fijamos en el siglo XVI donde sólo aparece un documento $(0,5 \%)$. Veamos la distribución cronológica de la documentación a modo de tabla y gráfica: 
Tabla 6. Análisis cronológico. Elaboración propia

\begin{tabular}{|c|c|c|c|}
\hline \multicolumn{4}{|c|}{ ANÁLISIS CRONOLÓGICO } \\
\hline & AÑOS & DOCS. & DOCS./SIGLO \\
\hline s. XVI & 1593 & 1 & 1 \\
\hline \multirow{3}{*}{ s. XVII } & 1628 & 1 & \multirow{3}{*}{3} \\
\hline & 1661 & 1 & \\
\hline & 1677 & 1 & \\
\hline \multirow{11}{*}{ s. XVIII } & 1720 & 1 & \multirow{11}{*}{12} \\
\hline & 1770 & 2 & \\
\hline & 1771 & 1 & \\
\hline & 1772 & 1 & \\
\hline & 1777 & 1 & \\
\hline & 1779 & 1 & \\
\hline & 1788 & 1 & \\
\hline & 1792 & 1 & \\
\hline & 1796 & 1 & \\
\hline & 1798 & 1 & \\
\hline & 1799 & 1 & \\
\hline \multirow{21}{*}{ s. XIX } & 1800 & 2 & \multirow{21}{*}{174} \\
\hline & 1801 & 2 & \\
\hline & 1802 & 1 & \\
\hline & 1803 & 2 & \\
\hline & 1808 & 1 & \\
\hline & 1812 & 1 & \\
\hline & 1814 & 1 & \\
\hline & 1815 & 3 & \\
\hline & 1816 & 2 & \\
\hline & 1820 & 4 & \\
\hline & 1821 & 98 & \\
\hline & 1822 & 27 & \\
\hline & 1823 & 1 & \\
\hline & 1824 & 5 & \\
\hline & 1825 & 1 & \\
\hline & 1826 & 1 & \\
\hline & 1830 & 2 & \\
\hline & 1832 & 2 & \\
\hline & 1834 & 1 & \\
\hline & 1835 & 1 & \\
\hline & 1836 & 1 & \\
\hline
\end{tabular}




\begin{tabular}{|l|l|l|}
\hline \multirow{4}{*}{} & 1848 & 1 \\
\cline { 2 - 3 } & 1849 & 2 \\
\cline { 2 - 3 } & 1851 & 2 \\
\cline { 2 - 3 } & 1852 & 1 \\
\cline { 2 - 3 } & 1853 & 2 \\
\cline { 2 - 3 } & 1857 & 1 \\
\cline { 2 - 3 } & 1858 & 4 \\
\cline { 2 - 3 } & 1860 & 1 \\
\cline { 2 - 3 } & 1869 & 1 \\
\hline
\end{tabular}

En este orden de cosas debemos señalar que existen 3 documentos cuya fecha de datación se fija en el siglo XVII (1,5\%), 12 se datan en el siglo XVIII (6,5 \%), concentrándose el mayor volumen documental en el siglo XIX con 174 documentos $(91,5 \%)$.

Figura 3. Análisis cronológico

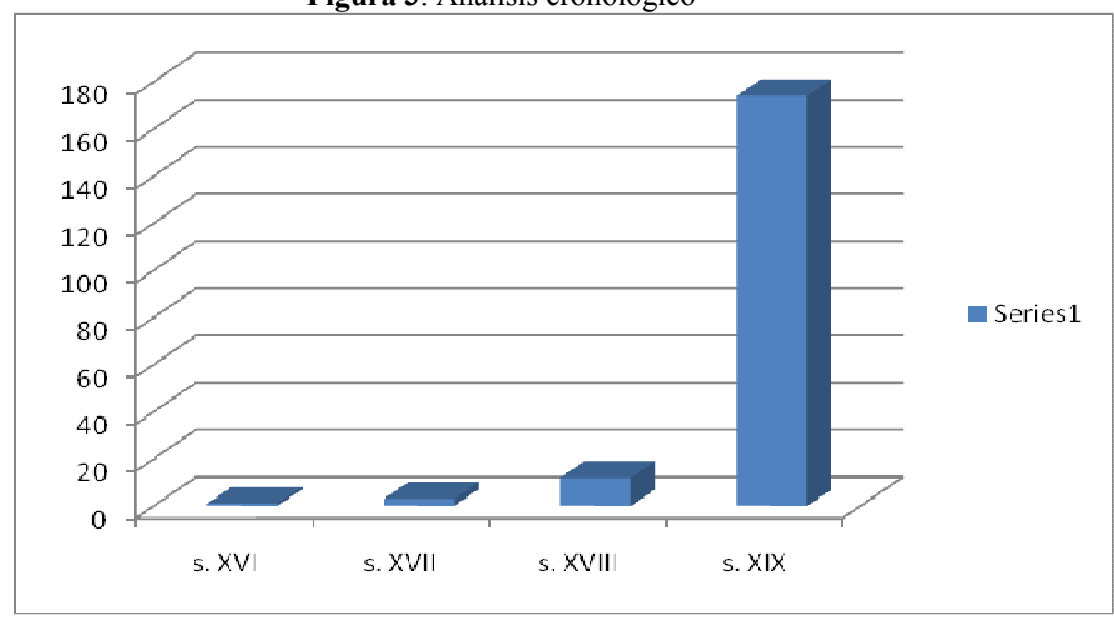

Como pueden observar, la mayor concentración documental se sitúa en 1821 y se debe fundamentalmente al gran número de secularizaciones perpetuas y temporales que se tramitan en dicho periodo, como consecuencia directa de las leyes y medidas supresoras que desde el Estado español se estaban formulando contra la Iglesia católica y muy especialmente contra sus conventualidades, que se vieron duramente afectadas mermando en número y en bienes. Este hecho condiciona la mayor tramitación de expedientes secularizadores que se dieron en la Iglesia y está documentación es prueba fidedigna de ello. 


\subsection{ANÁLISIS DE CONTENIDOS}

Los contenidos principales son los siguientes:

1. Secularizaciones. Se trata del tema más relevante de los que aparecen en la documentación objeto de nuestro análisis, dado que se muestra en 141 ocasiones, es decir, en el 74,2 \% del total. Por consiguiente, el resto de los contenidos que aparecen en esta documentación aportan un volumen documental escaso, lo que reduce la importancia de los mismos, aunque bien es cierto que la documentación dispositiva, emitida desde el Ministerio de Gracia y Justicia, es de suma relevancia para la historia de la conventualidad española porque la condicionó en su devenir histórico.

Las secularizaciones se focalizan en torno al año de 1821, cuestión obvia si tenemos en cuenta que las medidas supresoras más estrictas y especialmente la Ley de Desalojo Conventual se datan en torno al año de 1820. Las secularizaciones, temporales y perpetuas, muestran una relación causa-efecto directa con dichas medidas. Además, aparecen en todas las conventualidades y afectan casi por igual a las clausuras masculinas y femeninas de la baja Extremadura.

En este caso, la aparición de Madrid en la data tópica viene condicionada a que es en dicha ciudad donde se ubica la sede de la Nunciatura Apostólica Española. Las Nunciaturas, como órgano máximo de representación de la Santa Sede en nuestro país, tenían la misión de validar las secularizaciones después de haber sido autorizadas en los respectivos obispados.

Fundamentada la importancia de este contenido en su amplio volumen documental, casi un $75 \%$ del total, hace referencia al mismo, aportamos un documento que nos permitirá conocer en mayor profundidad este proceso, nos situará en el momento clave en el que interviene la Nunciatura Apostólica Española (Madrid) y nos permitirá conocer más ampliamente un procedimiento que según la documentación analizada fue clave en la conventualidad del primer tercio del siglo XIX. 


ADME/BA-CONVENTO-24-475
1822, junio,10/1822,(julio),5.Badajoz-Madrid
Secularización de Lorenzo Barragán del convento de San
Gabriel de Badajoz.
Manuscrito e impreso; 5 folios; Castellano y Latín; Buena
Contiene:
-1822, junio, 10.Badajoz.
Atestado del gobierno en el que Juan manifiesta sus deseos para
secularizarse, firmado por el jefe del Gobierno Político de Extremadura
Luis del Castillo. (1 folio impreso)
-1822, junio, 14.Badajoz.
Recibo del pago de tasas para secularización.
-1822, junio, 14.Badajoz.
Súplica del religioso para que le sea concedida secularización
perpetua.
-1822, junio, 28.Madrid.
Breve de secularización emitido por la Nunciatura Apostólica
Española (Latín)
-1822, (julio), 5.Badajoz.
Auto por el que el vicario Gabriel Blázquez concede permiso para la
secularización.

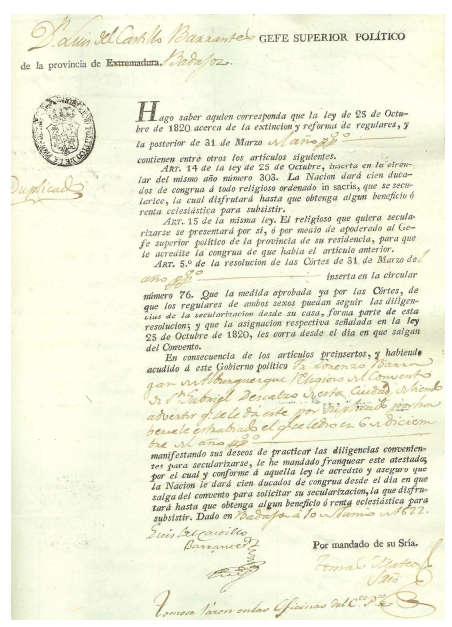

Documento emitido por el Gobierno Político de Extremadura. Esta parte se incluye en la gran mayoría de los expedientes de secularización. Se trata de un documento que se expide por el Gobierno Político de nuestra provincia y que da fe de la petición para la obtención de la secularización. En muchos casos suele ir acompañado de un pequeño recibo que acredita el pago de tasas necesarias para los trámites.

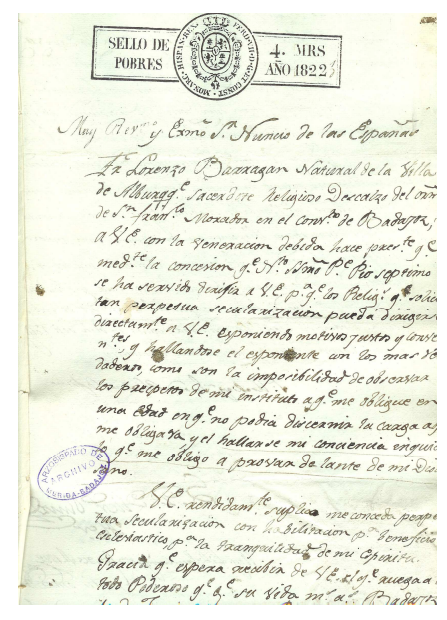

Súplica emitida por el religioso para que le sea concedida la secularización que solicita. En ella se suele reflejar tanto el motivo que le lleva a solicitar la secularización como la periodicidad de la misma (temporal o perpetua) 


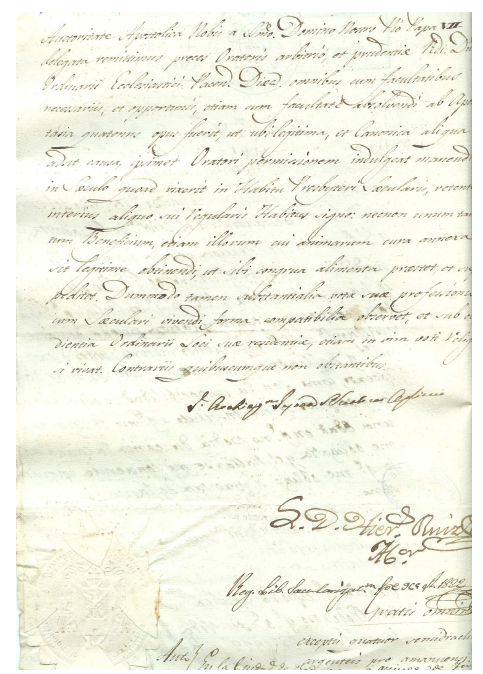

Breve Pontificio que otorga o no la secularización al suplicante. En este caso, se expide el breve concediendo la secularización. Esta parte del documento se expide desde la Nunciatura Apostólica española (Madrid) y utiliza la lengua latina.

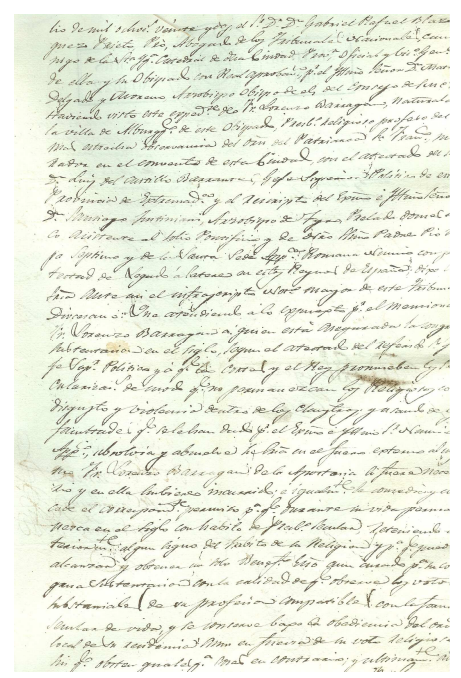

Resolución Obispal concediendo el permiso para la secularización solicitada. Esta parte del documento corresponde al obispo y supone la concesión definitiva de la secularización solicitada.

2. Ley de desalojo conventual de 25 de octubre de 1820 . Muy relacionada con la documentación anterior, aunque dispar en volumen (2 agrupaciones documentales que suponen el 1\%), aparece esta documentación. Se trata del documento que, expedido desde el Ministerio de Gracia y Justicia, se envía a los conventos extremeños comunicándoles el cierre del mismo, la disposición de sus integrantes y de sus enseres, tras las medidas supresoras desarrolladas por el Gobierno español en el primer tercio del siglo XIX.

Esta documentación es enviada a un numeroso grupo de conventos en nuestra provincia. Prueba de ello es que la data tópica de los documentos en cuestión refleja además de la ciudad de Madrid (sede de la entidad emisora) a poblaciones como Salvatierra de los Barros; Oliva de la Frontera; Jerez de los Caballeros; Alconchel; Villalba de los Barros; Zafra; Alburquerque; Burguillos; La Lapa; y Badajoz (sede de los conventos receptores de dicha Ley).

3. Real orden de $\mathbf{2}$ de mayo de $\mathbf{1 8 2 2}$ pidiendo razón de los religiosos y monjes secularizados. Siguiendo la temática marcada, este documento es desarrollada desde el Ministerio de Gracia y Justicia como consecuencia directa de 
la multitud de secularizaciones que desde todos los conventos españoles (sirvan de ejemplo los extremeños) se han tramitado en el año anterior y tras la puesta en marcha de la Ley de Desalojo Conventual de 1820. En 1822 el Gobierno español quiere conocer cuál es la situación real de los conventos extremeños y hacer un balance exhaustivo de los mismos. Por ello, envía desde Madrid esta Real orden a poblaciones como La Lapa; Fregenal de la Sierra; Zafra; Ceclavín; Oliva de la Frontera; Almendral; Jerez de los Caballeros.

4. Real orden de 20 de octubre de $\mathbf{1 8 2 2}$ sobre traslación de varios religiosos. Hasta tres documentos dan prueba de este proceso que llegó a ser habitual en las clausuras. Una vez se produce el cierre de los conventos establecidos, aquellos religiosos que no optaron por la secularización son reubicados, desde el poder civil no el eclesiástico, en otros conventos de la misma orden en poblaciones donde hubieran permanecido abiertos.

5. Distribución de objetos de los conventos suprimidos. Como hemos señalado en líneas anteriores, el Ministerio de Gracia y Justicia (Madrid) no sólo se preocupó de los religiosos que habitaban las clausuras. En 1835 emite disposiciones que obligan a los conventos a entregar al Estado sus enseres y pertenencias entre las que se encontraban objetos litúrgicos y ornamentales, libros, piezas de arte, etc.

6. Reales órdenes sobre conventos que deben permanecer abiertos en la provincia de Badajoz. Al igual que los contenidos anteriores este documento da nueva prueba de la situación que se vive en los conventos pacenses. Se expide desde el Ministerio de Gracia y Justicia en el año 1836 para indicar, al contrario que los documentos anteriores, los conventos que deben permanecer abiertos porque cumplen con los requisitos mínimos que imponen el Estado español y poder ofrecer de este modo servicios religiosos a las poblaciones donde se ubican.

7. Salidas temporales de conventos. Aportan un total de 8 agrupaciones documentales y suponen en algunos casos un paso previo a la petición de secularización. Para algunos religiosos era una vía no definitiva por la que optaron a principios del siglo XIX. Les proporcionaba poder salir de la clausura temporalmente, evitando así las fuertes medida dictadas por el poder civil, sin llegar a abandonar la orden en la que profesaron.

Además aparecen otra serie de contenidos de menor relevancia condicionados por el escaso volumen documental que representan. Algunos se relacionan con la Nunciatura Apostólica española (vertiente eclesiástica): toma de hábitos y profesiones perpetuas, cuentas de reparación, libros prohibidos, elecciones conventuales, venta de propiedades, rentas, y otros con el Ministerio de Gracia y 
Justicia (vertiente civil): Real Cédula por la que se restablece la Compañía de Jesús en España, privilegios, conservación de Iglesias, etc.

\section{CONCLUSIONES}

- Es conveniente reseñar que Madrid resulta ser la población, sita fuera de la demarcación extremeña, de la que se custodia un mayor volumen documental en el Archivo Diocesano de Mérida-Badajoz, vinculada a los contenidos y procedencia conventual.

- Cabe decir que se trata de una documentación muy específica. En la mayoría de casos, concluimos que son documentos dispositivos sobre medidas supresoras relativas conventualidades, y están emitidas por entidades cuya sede se localizaba en la ciudad madrileña.

- Se trata de una documentación sumamente relevante para el estudio de una etapa de la Iglesia católica afectada por numerosas medidas supresoras del Estado español. Es por tanto, una documentación de sumo interés para el estudio del primer tercio del siglo XIX en el marco eclesiástico.

- La Nunciatura Apostólica, como institución eclesiástica, y el Ministerio de Gracia y Justicia, como institución civil, son las entidades fundamentales que intervienen en las conventualidades mencionadas. La primera en asuntos como concesión de pensión alimenticia a conventos, cuentas de reparación, elecciones conventuales, estado ruinoso de entidades conventuales, libros prohibidos, patronazgo, petición de religiosas para seguir habitando un convento, pleitos, privilegios de diezmos, salidas temporales de conventos, secularizaciones (temporales y perpetuas), toma de hábito y profesión perpetua y venta propiedades conventualidad. La segunda decidió qué conventos podían permanecer abiertos y cuáles tenían que cerrar sus puertas porque no cumplían con el número mínimo de religiosos/as, participó en la distribución de los religiosos de los conventos suprimidos a otros que permanecían abiertos y condicionó la distribución de sus enseres y pertenencias,

- En definitiva, la documentación estudiada nos permite observar cómo la documentación conventual custodiada en el Archivo Diocesano de MéridaBadajoz no es una documentación aislada sino que ha mantenido flujos comunicativos con entidades de diversas procedencias. De este modo podremos acceder a instituciones, contenidos, personajes, etc relacionados con la historia conventual extremeña.

\section{CATÁLOGO DOCUMENTAL}

\section{ADME/BA-CONVENTO-9-187}

1815,octubre,6/1815,octubre,31.Badajoz-Madrid

Expediente de nulidad de una venta efectuada por el convento de Santo Domingo. Manuscrito; 8 folios; Castellano; Buena 
2. ADME/BA-CONVENTO-9-184

1815,octubre,6. Madrid.1815,octubre,10. Badajoz

Venta de una huerta perteneciente al convento de Santo Domingo de Badajoz.

Manuscrito; 8 folios; Castellano; Buena

3. ADME/BA-CONVENTO-10-200

1821,mayo, 29. Madrid/ 1821,junio, 26. Villanueva del Fresno- Badajoz-LlerenaAlmendral-Olivenza-Plasencia-Valverde de Leganés.

Expediente de ejecución de suspensión de conventos en la provincia de Badajoz. Manuscrito; 23 folios y 8 cuartillas; Castellano; Buena

4. ADME/BA-CONVENTO-10-201

1820,mayo,15.Badajoz/ 820,diciembre,22. Salvatierra- Madrid-Oliva-Jerez de los Caballeros-Alconchel-Villalba-Zafra-Alburquerque-Burguillos-La Lapa.

Sobre la aplicación de la ley de desalojo conventual (25 de octubre de 1820) en los conventos de la provincia de Badajoz. Manuscrito e impreso; 30 folios, 19 cuartillas y 1 folio doble; Castellano; Buena

5. ADME/BA-CONVENTO-10-211

1770,mayo,17.Badajoz/ 1772,junio,6.Madrid.

Confirmación de la renta que goza el predicador jubilado Francisco Tomás de Solís Ardila del Convento de la Santísima Trinidad de Badajoz.

Manuscrito; 39 folios; Castellano y Latín; Buena

6. ADME/BA-CONVENTO-10-216

1815,junio,17. Madrid

Real Cédula por la que se restablece la Compañía de Jesús.

Impreso; 3 folios; Castellano; Buena

7. ADME/BA-CONVENTO-17-298

1849, abril,29.Madrid/ 1849,junio,20.Badajoz

Obras del noviciado de las Hermanas de la Caridad.

Manuscrito e impreso; 7 folios y 4 cuartillas; Castellano; Bueno

8. ADME/BA-CONVENTO-17-300

1822,abril,10.Badajoz/1822,junio,31.La Lapa-Fregenal-Zafra-Ceclavín-Oliva-

Almendral-Jerez de los Caballeros-Madrid

Real orden de 2 de mayo de 1822 pidiendo razón de los religiosos y monjes secularizados, así como de los religiosos ausentes de sus comunidades desde 20/9/1821. Manuscrito; 26 folios; Castellano; Buena

9. ADME/BA-CONVENTO-17-301

1822,octubre,20/ 1823,enero,21. Madrid-Oliva-Cazalla de la Sierra-Zafra

Real orden de 20/10/1822 sobre traslación de varios religiosos de Zafra y La Lapa. Manuscrito; 6 folios (2 folios en blanco) y 5 cuartillas; Castellano; Buena

10. ADME/BA-CONVENTO-17-(4)

1849,mayo, 12.Madrid

Elección de seglares en la diócesis. Manuscrito; 1 folio; Castellano; R (documento incompleto)

11. ADME/BA-CONVENTO-24-455

1821,mayo,10/1821,noviembre, 17.Badajoz-Madrid

Secularización perpetua de Antonia Fabia del convento de las Mercedes Descalzas de Badajoz. Manuscrito; 4 folios; Castellano y Latín; Buena 
12. ADME/BA-CONVENTO-24-457

1848,mayo,22 /1848,junio,8.Badajoz-Madrid

Secularización temporal de María del pilar Núñez del convento de Santa Ana de Badajoz. Manuscrito; 8 folios; Castellano y Latín; Buena

13. ADME/BA-CONVENTO-24-461

1771,noviembre,7.Madrid/ 1771,noviembre,30.Badajoz

Secularización perpetua de fray Carlos José Correa del convento de la Santísima

Trinidad de Badajoz. Manuscrito; 11 folios y 2 cuartillas; Castellano y Latín; Buena

14. ADME/BA-CONVENTO-24-462

1770,octubre,3/ 1771,septiembre,13.Badajoz-Madrid.

Secularización perpetua de Lorenzo González Orduña del convento de la Santísima Trinidad de Badajoz. Manuscrito; 21 folios; Castellano y Latín; Buena

15. ADME/BA-CONVENTO-24-463

1869,enero,26.Badajoz/ 1870,marzo,26.Madrid-Roma

Secularización perpetua de Sor Ana González del Pilar del convento de los Remedios de Badajoz. Manuscrito; 16 folios y 6 cuartillas; Castellano y Latín; Buena

16. ADME/BA-CONVENTO-24-464

1821,junio,2/ 1830,diciembre,3.Badajoz-Madrid

Secularización perpetua de Juan y Micaela Vázquez en el convento de las Mercedes Descalzas de Badajoz. Manuscrito; 12 folios y 1 cuartilla; Castellano y Latín; Buena

17. ADME/BA-CONVENTO-24-468

1821,mayo,28/ 1822,septiembre,26.Badajoz-Madrid

Secularización perpetua de Tomás Parente del convento extinguido de Santo Domingo de Badajoz. Manuscrito e Impreso; 4 folios; Castellano y Latín; Buena

18. ADME/BA-CONVENTO-24-469

1822,septiembre,13/1822,octubre,6.Badajoz-Madrid

Secularización perpetua de Rafael Millán del convento de Santo Domingo de Badajoz. Manuscrito e impreso; 4 folios; Castellano y Latín; Buena

19. ADME/BA-CONVENTO-24-470

1822,septiembre,20/1822,octubre,31.Badajoz-Madrid.

Secularización perpetua de Juan Arias Flores del convento de San Francisco de Badajoz. Manuscrito e impreso; 4 folios; Castellano y Latín; Buena

20. ADME/BA-CONVENTO-24-471

1822,julio,11-1822,octubre,30.Badajoz-(Madrid)

Secularización perpetua de Diego Pérez del convento de San Gabriel de Badajoz. Manuscrito e impreso; 4 folios; Castellano y Latín; Buena

21. ADME/BA-CONVENTO-24-472

1821,abril,14/1822,mayo,25.Badajoz-Madrid

Secularización de Laureano Hernández del convento de Santo Domingo de Badajoz. Manuscrito e impreso; 4 folios; Castellano y Latín: Buena

22. ADME/BA-CONVENTO-24-473

1822,junio,18/1822,octubre,18.Badajoz-Madrid

Secularización de Juan Luna del convento de San Gabriel de Badajoz.

Manuscrito e impreso; 4 folios; Castellano y latín; Buena 


\section{ADME/BA-CONVENTO-24-474}

1822,mayo,20.Madrid/1822,octubre,29.Badajoz

Secularización perpetua de Manuel Garay del convento de San Gabriel de Badajoz. Manuscrito; 3 folios; Castellano y Latín; Buena

24. ADME/BA-CONVENTO-24-475

1822,junio, 10/1822, (julio),5.Badajoz-Madrid

Secularización de Lorenzo Barragán del convento de San Gabriel de Badajoz.

Manuscrito e impreso; 5 folios; Castellano y Latín; Buena

25. ADME/BA-CONVENTO-24-476

1822,septiembre,19/1822, noviembre,3.Badajoz-Madrid

Secularización de fray Miguel Parra del convento de San Francisco de Badajoz.

Manuscrito e impreso; 5 folios; Castellano y Latín; Buena

26. ADME/BA-CONVENTO-24-477

1822,marzo,2/1822, marzo,26.Badajoz-Madrid.

Secularización de Rita Laguna religiosa del convento de Santa Ana de Badajoz.

Manuscrito e impreso; 5 folios; Castellano y Latín; Buena

27. ADME/BA-CONVENTO-24-478

1822,septiembre,3/1822,octubre,11.Badajoz-Madrid.

Secularización de Tomás Olmos del convento de San Francisco de Badajoz.

Manuscrito; 3 folios y 1 cuartilla; Castellano y Latín; Buena

28. ADME/BA-CONVENTO-24-479

1822,febrero,14/ 1822, julio,4.Badajoz.-Madrid.

Secularización de José Arenas del convento de Santo Domingo de Badajoz.

Manuscrito e impreso; 5 folios; Castellano y Latín; Buena

29. ADME/BA-CONVENTO-24-480

1822,agosto,23/1822, octubre,7.Badajoz-Madrid

Secularización de Faustino Izquierdo del convento de Santo Domingo de Badajoz. Manuscrito e impreso; 5 folios; Castellano y Latín; Buena

30. ADME/BA-CONVENTO-24-481

1822,septiembre,19/1822, noviembre,10.Badajoz-Madrid.

Secularización de Antonio Gordillo del convento de San Francisco de Badajoz.

Manuscrito e impreso; 5 folios; Castellano y Latín; Buena

31. ADME/BA-CONVENTO-24-482

1822,septiembre,19/1822, octubre,7.Badajoz-Madrid.

Secularización de Alonso Rodríguez prior del convento de Santo Domingo de

Badajoz. Manuscrito e impreso; 4 folios; Castellano y Latín; Buena

32. ADME/BA-CONVENTO-24-483

1821,enero,30/1821,noviembre,5.Badajoz-Madrid

Secularización de Rosalía de la Presentación del convento de las Mercedes Descalzas de Badajoz. Manuscrito; 4 folios; Castellano y Latín; Buena

33. ADME/BA-CONVENTO-24-484

1821,mayo,13/ 1821,septiembre,11.Badajoz-Madrid

Secularización de Francisco González Gatreno del convento de la Trinidad de Badajoz. Manuscrito; 4 folios; Castellano y Latín; Buena

34. ADME/BA-CONVENTO-24-485

1821,mayo,28/1822,octubre,16.Badajoz-Madrid 
Secularización perpetua de Antonio Olivera del convento de Santo Domingo de Badajoz. Manuscrito e impreso; 4 folios; Castellano y Latín; Buena

35. ADME/BA-CONVENTO-24-486 1821, agosto,30/1821,noviembre,23.Badajoz-Madrid

Secularización de Fray José Mendoza del convento de la Trinidad de Badajoz. Manuscrito; 4 folios; Castellano y Latín; Buena

36. ADME/BA-CONVENTO-24-487

1821,noviembre, $8 / 1822$, enero,13.Badajoz-Madrid

Secularización de Agustín Barragán del convento de San Francisco de Badajoz. Manuscrito; 5 folios; Castellano y Latín; Buena

37. ADME/BA-CONVENTO-24-488

1821,mayo,15/ 1821,septiembre,12.Badajoz-Madrid.

Secularización de Matías Santos del convento de San Gabriel de Badajoz. Manuscrito; 5 folios; Castellano y Latín; Buena

38. ADME/BA-CONVENTO-24-489

1821,marzo,11/1822,marzo,20.Badajoz-Madrid.

Secularización de María Rodríguez en el convento de las Mercedes Descalzas de Badajoz. Manuscrito e impreso; 4 folios; Castellano y Latín; Buena

39. ADME/BA-CONVENTO-24-490

1821,agosto,10/1822, diciembre,20.Badajoz-Madrid.

Secularización de Sebastián Caballero del convento de Santo Domingo de Badajoz. Manuscrito; 4 folios; Castellano y Latín; Buena

40. ADME/BA-CONVENTO-24-491

1822,septiembre,19/1822,noviembre,3.Badajoz-Madrid.

Secularización de José López del convento de San Francisco de Badajoz. Manuscrito; 5 folios; Castellano y Latín; Buena

41. ADME/BA-CONVENTO-24-492

1822,febrero,2.Madrid/1822,marzo,26.Badajoz.

Secularización de Ramona Laguna del convento de Santa Ana de Badajoz. Manuscrito; 4 folios; Castellano y Latín; Buena

42. ADME/BA-CONVENTO-24-493

1822,mayo,21/1822,octubre,29.Cáceres-Badajoz-Madrid.

Secularización de Diego Ramos del convento de Santo Domingo de Badajoz. Manuscrito; 6 folios; Castellano y Latín; Buena

43. ADME/BA-CONVENTO-24-494

1821,octubre,27/1822, agosto,14.Badajoz-Madrid

Secularización de Manuel Díez del convento de San Francisco de Badajoz. Manuscrito; 4 folios; Castellano y Latín; Buena

44. ADME/BA-CONVENTO-24-495

1821,enero,30/1822,octubre,26.Badajoz-Madrid.

Secularización de Ana García del convento de las Mercedes Descalzas de Badajoz.

Manuscrito; 4 folios; Castellano y Latín; Buena 
45. ADME/BA-CONVENTO-24-496

1821,julio,5.Jerez de los Caballeros/1821,agosto,20.Badajoz-Madrid-Jerez de los Caballeros.

Secularización de Diego Villarroel del convento extinguido de San Agustín de Badajoz. Manuscrito; 9 folios; Castellano y Latín; Buena

46. ADME/BA-CONVENTO-24-497

1820,noviembre,16/ 1821,mayo,17.Badajoz-Madrid-Oliva de la Frontera.

Secularización de Dionisio Guerrero del convento de la Santísima Trinidad de Badajoz. Manuscrito; 7 folios; Castellano y Latín; Buena

47. ADME/BA-CONVENTO-24-498

1821,mayo,28 /1821,agosto,27.Badajoz-Madrid.

Secularización de Diego Cano Borega del convento extinguido de San Agustín de Badajoz. Manuscrito; 8 folios; Castellano y Latín; Buena

48. ADME/BA-CONVENTO-24-499

1821,febrero,22/ 1821,octubre,30.Badajoz-Madrid.

Secularización de Josefa Delgado del convento de Santa Ana de Badajoz.

Manuscrito; 4 folios; Castellano y Latín; Buena

49. ADME/BA-CONVENTO-424-17479n 18

1853,Julio,(sd)Madrid/1853,Octubre,25.Llerena-Almendralejo

Secularización perpetua de Sor María González religiosa del convento de Santa Clara de Almendralejo. Manuscrito; 3 folios y 4 cuartillas; Castellano y Latín; Buena

50. ADME/BA-CONVENTO-16-296

1808,febrero,24.Badajoz/(sd).Madrid

Venta de una casa perteneciente al convento Madre de Dios de Valverde de Badajoz para pagar unas deudas. Manuscrito; 9 folios y 1 cuartilla; Castellano; $\mathrm{R}$ (roturas)

51. ADME/BA-CONVENTO-20-(14)

1835,septiembre,9.Madrid-(Badajoz)

Distribución de objetos de los conventos suprimidos. Manuscrito; 1 folio; Castellano; Buena

52. ADME/BA-CONVENTO-20 bis-(9)

1824,abril,28/1824,agosto,5.Alburquerque-Madrid.

Toma de hábito y profesión perpetua de María Felipa del Sacramento en el convento de la Encarnación de Alburquerque. Manuscrito; 7 folios y 1 cuartilla; Castellano; Buena

53. ADME/BA-CONVENTO-20 bis-(21)

1824,noviembre,2/ 1824,diciembre,24.Bararrota-Jerez de los Caballeros-Madrid

Ratificación de la profesión de María del Corazón de Jesús del convento de la Asunción de Barcarrota. Manuscrito; 3 folios y 1 cuartilla; Castellano; Buena

54. ADME/BA-CONVENTO-20 bis-(95)

1832,octubre,13/ 1824,diciembre,12.Jerez de los Caballeros -Madrid-Badajoz

Ratificación de la profesión de Mariana López de Ayala en el convento de la Trinidad de Jerez de los Caballeros.

Manuscrito; 6 folios y 1 cuartilla; Castellano; Buena

55. ADME/BA-CONVENTO-20 bis-(96)

1858,junio,7.Madrid/ 1858, junio,20.Badajoz-La Parra 
Toma de hábito de María del Carmen Rodríguez en el convento de los Dolores de la Parra. Manuscrito; 5 folios ( 2 folios en blanco) y 1 cuartilla; Castellano; Buena

56. ADME/BA-CONVENTO-11-450n ${ }^{\circ}$

1853,noviembre,16/1862,febrero,17.Badajoz-Madrid

Cuentas de reparación del convento de las Mercedes Descalzas de Badajoz.

Manuscrito; 16 folios (2 folios en blanco); Castellano; Buena

57. ADME/BA-CONVENTO-18-357

1834,julio,31.Madrid/ 1834,agosto,1.Badajoz

Entrega de enseres del convento suprimido de Santo Domingo de Badajoz.

Manuscrito; 1 cuartilla; Castellano; Buena

58. ADME/BA-CONVENTO-18-(3)

1824, febrero,24.Madrid/ 1824,marzo,6.Badajoz

Libros prohibidos. Manuscrito; 2 folios; Castellano; Buena

59. ADME/BA-CONVENTO-23-434

1851.Madrid

Monjas Clarisas sobre privilegios de diezmos. Manuscrito; 2 folios; Castellano; Buena

60. ADME/BA-CONVENTO-23-451

1800,abril,26.Villanueva del Fresno/ 1814,diciembre,23.Madrid-Jerez de los

Caballeros

Vida fuera de la clausura de tres religiosas del convento Madre de Dios de Jerez de los Caballeros. Manuscrito; 19 folios; Castellano; Buena

61. ADME/BA-CONVENTO-23-452

1823,marzo,6.Badajoz/ 1826,enero,19.Madrid

Entrada al convento de Santa Ana de Badajoz de Gabriela Valencia, secularizada. Manuscrito; 15 folios (3 folios en blanco); Castellano; Buena

62. ADME/BA-CONVENTO-23-(11)

1836,abril,5/ 1837,julio,13.Madrid

Reales Órdenes sobre conventos que deben permanecer abiertos en la provincia de Badajoz. Manuscrito; 15 folios; Castellano; Buena

63. ADME/BA-CONVENTO-25-507

1816,agosto,7/1817,julio,28.Badajoz-Sevilla-Madrid-Roma

Secularización perpetua de José Alvarado del convento de Santo de San Agustín de Badajoz. Manuscrito; 30 folios (hasta el 20 numerados) y 1 cuartilla; Castellano y Latín; Buena

64. ADME/BA-CONVENTO-25-511

1821,mayo,14/ 1821,diciembre,16.Badajoz-Madrid

Secularización perpetua de Calixta Lobo, religiosa de velo negro del convento Madre de Dios de Valverde de Badajoz. Manuscrito; 4 folios; Castellano y Latín; Buena

65. ADME/BA-CONVENTO-25-512

1821,marzo,6/1821,agosto,29.Badajoz-Valdeobispo-Madrid

Secularización perpetua de Ramón Mateos del convento de San Gabriel de Badajoz. Manuscrito; 7 folios; Castellano y Latín; Buena

66. ADME/BA-CONVENTO-25-513

1821,abril,9/ 1821,junio,1.Badajoz-Madrid

Secularización perpetua de Celedonio Gómez del convento de San Gabriel de Badajoz. Manuscrito; 4 folios; Castellano y Latín; Buena 
67. ADME/BA-CONVENTO-25-514

1821,marzo,9/ 1821,abril,26.Badajoz-Madrid

Secularización de Pedro Moro Bueno del convento de San Agustín de Badajoz.

Manuscrito; 5 folios; Castellano y Latín; Buena

68. ADME/BA-CONVENTO-25-515

1821,marzo,6/ 1821,abril,30.Badajoz-Madrid

Secularización perpetua de Juan Martínez del convento de San Francisco de Badajoz. Manuscrito; 6 folios; Castellano y Latín, Buena

69. ADME/BA-CONVENTO-25-516

1821,junio,19/ 1821,diciembre,19.Badajoz-Madrid

Secularización perpetua de José de Leba del convento de Santo Domingo de Badajoz.

Manuscrito; 4 folios; Castellano y Latín; Buena

70. ADME/BA-CONVENTO-25-517

1821,octubre,12/ 1821,octubre,29.Badajoz-Madrid

Secularización temporal de Isabel Vázquez, religiosa de velo negro, del convento de Santa Catalina de Badajoz.

Manuscrito; 4 folios; Castellano y Latín; Buena

71. ADME/BA-CONVENTO-25-518

1825,mayo,30/ 1825,julio,28.Badajoz-Madrid

Secularización perpetua de Claudio Barreros del convento de San Agustín de Badajoz. Manuscrito; 4 folios; Castellano y Latín; Buena

72. ADME/BA-CONVENTO-25-519

1821,enero,30/1821,octubre,26.Badajoz-Madrid

Secularización perpetua de María del Pilar Alvarado del convento de las Mercedes Descalzas de Badajoz. Manuscrito; 4 folios; Castellano y Latín; Buena

73. ADME/BA-CONVENTO-25-520

1821,mayo,7/1821,julio,24.Badajoz-Madrid

Secularización perpetua de Manuel Serrano del convento de las San Francisco de Badajoz. Manuscrito; 5 folios; Castellano y Latín; Buena

74. ADME/BA-CONVENTO-25-521

1821,febrero,10/ 1821,junio,14.Badajoz-Madrid

Secularización perpetua de Juan Vázquez del convento de las San Francisco de Badajoz. Manuscrito; 6 folios; Castellano y Latín; Buena

75. ADME/BA-CONVENTO-25-522

1821,junio,19/ 1821,octubre,8.Badajoz-Madrid

Secularización perpetua de Joaquín Polo del convento de Santo Domingo de Badajoz. Manuscrito; 4 folios; Castellano y Latín; Buena

76. ADME/BA-CONVENTO-25-523

1821,mayo,25/1821,diciembre,21.Badajoz-Madrid-Jerez de los Caballeros

Secularización perpetua de José Ardila del convento de San Agustín de Jerez de los Caballeros. Manuscrito; 4 folios; Castellano y Latín; Buena

77. ADME/BA-CONVENTO-25-524

1821,octubre,5/1821,noviembre,17.Badajoz-Madrid

Secularización perpetua de María del Carmen Martínez del convento de las Mercedes Descalzas de Badajoz. Manuscrito; 4 folios; Castellano y Latín; Buena 
78. ADME/BA-CONVENTO-25-525

1821,enero,30/ 1821,octubre,29.Badajoz-Madrid

Secularización perpetua de Isabel Fernández del convento de las Mercedes Descalzas de Badajoz.

Manuscrito; 4 folios; Castellano y Latín; Buena

79. ADME/BA-CONVENTO-25-526

1821,mayo,28/ 1821,noviembre,9.Badajoz-Madrid

Secularización perpetua de Francisco Gilés del convento de San Francisco de Badajoz. Manuscrito; 4 folios; Castellano y Latín; Buena

80. ADME/BA-CONVENTO-25-527

1821,septiembre,25/ 1821,octubre,30.Badajoz-Madrid

Secularización perpetua de $M^{a}$ Bárbara Domáica del convento de Santa Ana de Badajoz. Manuscrito; 4 folios; Castellano y Latín; Buena

81. ADME/BA-CONVENTO-25-528

1821,enero,30/1821,octubre,26.Badajoz-Madrid

Secularización perpetua de María Pilar Martín del convento de las Mercedes Descalzas de Badajoz. Manuscrito; 4 folios; Castellano y Latín; Buena

82. ADME/BA-CONVENTO-25-529

1821,marzo,11/ 1821,diciembre,29.Badajoz-Madrid

Secularización perpetua de María Soledad Martín del convento de las Mercedes Descalzas de Badajoz. Manuscrito; 4 folios; Castellano y Latín; Buena

83. ADME/BA-CONVENTO-25-530

1821,febrero,24/1821,octubre,29.Badajoz-Madrid

Secularización perpetua de Ana Roza del convento de Santa Catalina de Badajoz. Manuscrito; 4 folios; Castellano y Latín; Buena

84. ADME/BA-CONVENTO-25-531

1821,agosto,2/1821,octubre,26.Badajoz-Madrid

Secularización perpetua de Francisco Peláez del convento de San Gabriel de Badajoz. Manuscrito; 6 folios; Castellano y Latín; Buena

85. ADME/BA-CONVENTO-25-532

1821,junio,28/1821,agosto,20.Badajoz-Madrid

Secularización perpetua de Vicente Holgado del convento de San Agustín de Badajoz. Manuscrito; 2 folios; Castellano y Latín; Buena

86. ADME/BA-CONVENTO-25-533n ${ }^{01}$

1821,noviembre,5/ 1821,noviembre,23.Badajoz-Madrid

Secularización perpetua de Manuel Oliva del convento de San Francisco de Badajoz.

Manuscrito; 4 folios; Castellano y Latín; Buena

87. ADME/BA-CONVENTO-25-533n'2

1821,mayo,28/ 1821,octubre,20.Badajoz-Madrid

Secularización perpetua de Nicolás Ruano del convento de San Agustín de Badajoz. Manuscrito; 2 folios; Castellano y Latín; Buena

88. ADME/BA-CONVENTO-25-534

1821,febrero,24/ 1821,noviembre,17.Badajoz-Madrid

Secularización perpetua de Paula de Santa Inés del convento de Santa Catalina de Badajoz. Manuscrito; 4 folios; Castellano y Latín; Buena 
89. ADME/BA-CONVENTO-25-535

1821,febrero,25/1821,noviembre,8.Badajoz-Madrid

Secularización perpetua de Ana Blanco del convento de Santa Ana de Badajoz.

Manuscrito; 3 folios; Castellano y Latín; Buena

90. ADME/BA-CONVENTO-25-536n 1

1821,enero,30/1821,octubre,26.Badajoz-Madrid

Secularización perpetua de Juana Alvarado del convento de las Mercedes

Descalzas de Badajoz. Manuscrito; 4 folios; Castellano y Latín; Buena

91. ADME/BA-CONVENTO-25-536n ${ }^{\circ}$

1821,enero,30/1821,octubre,29.Badajoz-Madrid

Secularización perpetua de Juana Domínguez del convento de las Mercedes

Descalzas de Badajoz. Manuscrito; 4 folios; Castellano y Latín; Buena

92. ADME/BA-CONVENTO-25-536n'3

1822,marzo,11/1822,diciembre,24.Badajoz-Madrid

Secularización perpetua de María Henríquez del convento de las Mercedes

Descalzas de Badajoz. Manuscrito; 4 folios; Castellano y Latín; Buena

93. ADME/BA-CONVENTO-25-536n ${ }^{\circ} 4$

1821,mayo,10/ 1821,noviembre,11.Badajoz-Madrid

Secularización perpetua de María del Carmen Sáez, religiosa de velo negro, del convento de las Mercedes Descalzas de Badajoz. Manuscrito; 4 folios; Castellano y Latín; Buena

94. ADME/BA-CONVENTO-25-537n 1

1821,agosto,26/1821,octubre,19.Badajoz-Madrid

Secularización perpetua de Ramón Pardo del convento de Santo Domingo de Badajoz. Manuscrito; 4 folios; Castellano y Latín; Buena

95. ADME/BA-CONVENTO-25-537n 22

1821,agosto,20/1821,octubre,26.Badajoz-Madrid

Secularización perpetua de Matías Matamoro del convento de Santo Domingo de Badajoz. Manuscrito; 4 folios y 1 cuartilla; Castellano y Latín; Buena

96. ADME/BA-CONVENTO-25-538n 1

1820,noviembre,18/ 1821,junio,14.Badajoz-Madrid

Secularización temporal de Antonio García Vivas del convento de San Agustín de Badajoz. Manuscrito; 8 folios; Castellano y Latín; Buena

97. ADME/BA-CONVENTO-25-538n'2

1821,mayo,27/1821,agosto,25.Badajoz-Madrid

Secularización perpetua de Pedro Antón del convento de San Agustín de Badajoz. (1 folio). Manuscrito; 5 folios; Castellano y Latín; Buena

98. ADME/BA-CONVENTO-25-538n'3

1825,mayo,8/1825,junio,20.Badajoz-Madrid

Secularización perpetua de Lucas Fernández del convento de San Agustín de Badajoz. Manuscrito; 4 folios; Castellano y Latín; Buena

99. ADME/BA-CONVENTO-25-538n 4

1821,junio,26/1821,octubre,18.Badajoz-Madrid

Secularización perpetua de Miguel Sánchez del convento de San Agustín de Badajoz. Manuscrito; 4 folios; Castellano y Latín; Buena 
100. ADME/BA-CONVENTO-25-539n'1

1820,marzo,10/1821,abril,26.Badajoz-Madrid

Secularización perpetua de Manuel Amaya del convento de San Francisco de Badajoz. Manuscrito; 4 folios; Castellano y Latín; Buena

101. ADME/BA-CONVENTO-25-539n'2

1821,abril,2/1821,mayo,29.Badajoz-Madrid

Secularización perpetua de Juan de la Cruz del convento de San Francisco de Badajoz. Manuscrito; 5 folio; Castellano y Latín; Buena

102. ADME/BA-CONVENTO-25-539n'3

1821,febrero,27/1821,mayo,21.Badajoz-Madrid-Oliva de la Frontera

Secularización perpetua de Francisco Señas del convento de San Francisco de Badajoz. Manuscrito; 7 folios; Castellano y Latín; Buena

103. ADME/BA-CONVENTO-25-539n ${ }^{\circ}$

1821,abril,9/1821,mayo,12.Badajoz-Madrid

Secularización perpetua de Rafael Crespo del convento de San Gabriel de Badajoz. Manuscrito; 4 folios; Castellano y latín; Buena

104. ADME/BA-CONVENTO-25-539n'5

1821,enero,23/1821,abril,3.Badajoz-Madrid

Secularización perpetua de Fernando Ortiz del convento de San Gabriel de Badajoz. Manuscrito; 5 folios; Castellano y Latín; Buena

105. ADME/BA-CONVENTO-25-539n'6

1821,abril,13/1821,mayo,8.Badajoz-Madrid

Secularización perpetua de Juan Vargas del convento de San Gabriel de Badajoz. Manuscrito; 4 folios; Castellano y Latín; Buena

106. ADME/BA-CONVENTO-25-541n'1

1821,febrero,24/1821,octubre,29.Badajoz-Madrid

Secularización perpetua de Luciana Sosa del convento de Santa Catalina de Badajoz. Manuscrito; 4 folios; Castellano y Latín; Buena

107. ADME/BA-CONVENTO-25-541n'2

1821,diciembre,5/1821,diciembre,29.Badajoz-Madrid

Secularización perpetua de Paula Guerra del convento de San Onofre de Badajoz. Manuscrito; 4 folios; Castellano y Latín; Buena

108. ADME/BA-CONVENTO-25-547

1814,abril,26/1814,noviembre,12.Badajoz-Madrid

Secularización perpetua de Pablo Moro y Bueno del convento de San Agustín de Badajoz. Manuscrito; 6 folios; Castellano y Latín; Buena

109. ADME/BA-CONVENTO-25-549

1812,octubre,1/1816,septiembre,20.Badajoz-Madrid

Secularización temporal de Francisco Paula en el convento de San Francisco de Badajoz. Manuscrito; 25 folios; Castellano y latín; Buena

110. ADME/BA-CONVENTO-25bis-(48)

1824,noviembre,15/1824,diciembre,18.Badajoz-Madrid-Jerez de los Caballeros

Profesión perpetua de Luciana de San Esteban, secularizada, en el convento de Santa Catalina Badajoz. Manuscrito; 5 folios; Castellano; Buena 
111. ADME/BA-CONVENTO-25bis-(52)

1824,noviembre,15/1824,diciembre,18.Badajoz

Profesión perpetua de Ana de San Juan, secularizada, en el convento de Santa Catalina Badajoz. Manuscrito; 5 folios; Castellano; Buena

112. ADME/BA-CONVENTO-106-4526

1628,junio,19.Madrid/1628,julio,4.Guadalcanal-Mérida

Estudio de cuentas de los conventos de la localidad de Mérida.

Manuscrito; 2 folios; L. Procesal; Buena

113. ADME/BA-CONVENTO-122-5187

1822,octubre,10/1823,febrero,7.Segura de León-Madrid-Llerena

Secularización perpetua de Antonio Palacios del convento de San Benito de Segura de León. Manuscrito; 9 folios; Castellano y Latín; Buena

114. ADME/BA-CONVENTO-177-6933

1821,febrero, $15 / 1821$,abril,13.Llerena

Secularización perpetua de Francisco María Martín del convento de San Buenaventura de Llerena. Manuscrito; 5 folios; Castellano y Latín; Buena

115. ADME/BA-CONVENTO-177-6932

1821,enero,24/1821,mayo,12.Llerena-Madrid

Secularización perpetua de Juan Francisco Jimeno del convento de San Buenaventura de Llerena.

Manuscrito; 9 folios; Castellano y Latín; Buena

116. ADME/BA-CONVENTO-177-6934

1821,junio,28/1821,mayo,7.Llerena-Madrid

Secularización perpetua de Juan Gómez del convento de San Sebastián de Llerena. Manuscrito; 5 folios; Castellano y Latín; Buena

117. ADME/BA-CONVENTO-177-6935

1821,mayo,17/1821,julio,10.Llerena-Madrid

Secularización perpetua de Manuel Plaza del convento de San Sebastián de Llerena. Manuscrito; 7 folios (1 folio en blanco); Castellano y Latín; Buena

118. ADME/BA-CONVENTO-177-6936

1821, septiembre,7.Madrid/1822, agosto,26.Llerena

Secularización perpetua de Sebastián Villate del convento de la Merced de Llerena. Manuscrito; 5 folios; Castellano y Latín; Buena

119. ADME/BA-CONVENTO-177-6938

1821,junio,24/1821,agosto,2.Llerena-Madrid

Secularización perpetua de José Cisneros del convento de San Sebastián de Llerena. Manuscrito; 5 folios; Castellano y Latín; Buena

120. ADME/BA-CONVENTO-177-6939

1821,junio,19/1822,septiembre,9.Llerena-Madrid

Secularización perpetua de Vicente Barba del convento de San Buenaventura de Llerena. Manuscrito; 6 folios; Castellano y Latín; Buena

121. ADME/BA-CONVENTO-254-11086

1796, febrero,1.Madrid/1796,marzo,31.Llerena

Concesión de pensión alimenticia al convento de la Merced de Llerena.

Manuscrito; 11 folios; Castellano; Buena 
122. ADME/BA-CONVENTO-254-11097

1860,junio,25.Madrid/1860,octubre,27.Llerena

Reparación del convento de Santa Clara de Llerena.

Manuscrito; 5 folios y 4 cuartillas; Castellano; Buena

123. ADME/BA-CONVENTO-50-2511

1821,enero,20.Madrid/1821, abril,7.Llerena

Secularización perpetua de José Fernández del convento de San Benito de Segura de León.

Manuscrito; 14 folios y 1 cuartilla; Castellano y Latín; Buena

124. ADME/BA-CONVENTO-306bis-13931

1857,mayo,28.Segura de León/1857,junio,23.Madrid

Estado ruinoso del convento de la Concepción de Segura de León.

Manuscrito; 3 folios (1 folio en blanco); Castellano; Buena

125. ADME/BA-CONVENTO-481-(34)

1779,enero,30.Madrid/1779,febrero,9.Llerena

Toma de hábito de Constanza Mena en el convento de Santa Ana de Llerena.

Manuscrito; 5 folios (1 folio en blanco); Castellano y Latín; Buena

126. ADME/BA-CONVENTO-51-2586

1822,abril,24.Madrid/1822,julio,8.Llerena-Segura de León

Secularización de Pedro de la Cueva en el convento de San Benito de Segura de León. Manuscrito; 5 folios; Castellano y Latín; Buena

127. ADME/BA-CONVENTO-437-17823n 3

1822,enero, 12/1822,abril,20.Bienvenida-Llerena-Madrid

Secularización perpetua de Juana Benero en el convento de la Concepción de Bienvenida. Manuscrito; 7 folios; Castellano y Latín; Buena

128. ADME/BA-CONVENTO-437-17823n 4

1792,diciembre,7.Madrid/1792,diciembre,19.Bienvenida-Llerena

Dispensa de la clausura de Teresa y María José Chaves, religiosas del convento de la Concepción de Bienvenida. Manuscrito; 11 folios (2 folios en blanco); Castellano; Buena

129. ADME/BA-CONVENTO-504-20041

1802,agosto,11.Madrid-(Mérida)

Nulidad de profesión de Antonia Vallejo religiosa en el convento de Santa Clara de Mérida. Manuscrito; 2 folios; Castellano; Buena

130. ADME/BA-CONVENTO-504-20041bis

1830,enero,14.Madrid/1830,febrero,16.Llerena-Mérida

Secularización de la religiosa de velo negro María Morgado en el convento de la Santa Clara de Mérida. Manuscrito; 4 folios; Castellano y Latín; Buena

131. ADME/BA-CONVENTO-504-20041bis

1830,enero,14.Madrid/1830,febrero,16.Llerena-Mérida

Secularización de la religiosa de velo negro María Morgado en el convento de la Santa Clara de Mérida. Manuscrito; 4 folios; Castellano y Latín; Buena

131. ADME/BA-CONVENTO-482-19032bis

1821,noviembre,25/1822, junio,3.Llerena-Madrid

Secularización perpetua de Juana Nepomuceno, religiosa de velo negro, del convento de la Concepción de Llerena. Manuscrito; 5 folios;Castellano y Latín; Buena

132. ADME/BA-CONVENTO-482-19033

1821,abril,6/1821,diciembre,17.Llerena-Madrid 
Secularización perpetua de Antonia Dolores Zambrano del convento de la Concepción de Llerena. Manuscrito; 5 folios; Castellano y Latín; Buena

133. ADME/BA-CONVENTO-482-19047

1851,noviembre,22/1851,noviembre,23.Llerena

Visita al convento de Santa Clara de Llerena para afianzamiento de la Regla.

Manuscrito; 3 folios; Castellano; Buena

134. ADME/BA-CONVENTO-482-19063

1821,septiembre,29/1821,noviembre,6.Llerena-Madrid

Secularización perpetua de la religiosa Jacinta Durán en el convento de Santa Isabel de Llerena. Manuscrito; 7 folios; Castellano y Latín; Buena

135. ADME/BA-CONVENTO-482-19063bis

1821,marzo,20/1821,noviembre,6.Llerena-Madrid

Secularización perpetua de Antonia Cabeza en el convento de Santa Isabel de Llerena.

Manuscrito; 7 folios; Castellano y Latín; R (roturas)

136. ADME/BA-CONVENTO-482-(1)

1821,septiembre,26.Madrid/1821,noviembre,13.Llerena

Secularización perpetua de María Rodríguez en el convento de Santa Isabel de Llerena. Manuscrito; 5 folios y 1 cuartilla; Castellano y Latín; Buena

137. ADME/BA-CONVENTO-482-(2)

1821,septiembre,26.Madrid/1821,noviembre,13.Llerena

Secularización perpetua de Joaquina de San Francisco en el convento de Santa Isabel e Llerena. Manuscrito; 5 folios y 1 cuartilla; Castellano y Latín; Buena

138. ADME/BA-CONVENTO-482-(3)

1822,marzo,21/1822,mayo,22.Llerena-Madrid

Secularización perpetua de Encarnación López Jara en el convento de Santa Isabel de Llerena. Manuscrito; 4 folios y 2 cuartillas; Castellano; Buena

139. ADME/BA-CONVENTO-482-(4)

1822,marzo,21/1822,mayo,22.Llerena-Madrid

Secularización perpetua de María Josefa López en el convento de Santa Isabel de Llerena. Manuscrito; 4 folios; Castellano; Buena

140. ADME/BA-CONVENTO-483-19076

1803,mayo,23.Madrid-Llerena

Secularización de Felipe Espinosa del convento de San Buenaventura de Llerena. Manuscrito; 4 cuartillas; Latín; Buena

141. ADME/BA-CONVENTO-483-19078

1821,febrero,23/1821,mayo,7.Llerena-Madrid

Secularización perpetua de Fernando Trenado en el convento de San Buenaventura de Llerena. Manuscrito; 8 folios; Castellano y Latín; Buena

142. ADME/BA-CONVENTO-524-20658

1788,noviembre,25. Campillo de Llerena/1789,septiembre,29.Segura de LeónMadrid-Llerena.

Pago de cuentas de mayordomía en el convento de la Concepción de Segura de León. Manuscrito; 37 folios; Castellano; Buena

143. ADME/BA-CONVENTO-917-31072bis

1661,mayo,(sd).Madrid/1661,noviembre,7.Llerena 
Toma de hábito de María Espinosa en el convento de Santa Ana de Llerena. Manuscrito; 6 folios; L. Procesal; Buena

144. ADME/BA-CONVENTO-933-31422

1821,febrero,11.Mérida/1821,junio,15.Llerena

Secularización perpetua de Alonso Lobo religioso del convento de Nuestra Señora de la Antigua de Mérida. Manuscrito; 12 folios; Castellano; Buena

145. ADME/BA-CONVENTO-933-31423

1821,abril,15.Mérida/1821, agosto,26.Llerena

Secularización perpetua de Bartolomé Toro religioso del convento de Nuestra Señora de la Antigua de Mérida. Manuscrito; 13 folios; Castellano; Buena

146. ADME/BA-CONVENTO-1027-(6)

1858,junio,11.Madrid/1858,junio,16.Segura de León

Abono de la pensión de una religiosa del convento de la Concepción de Segura de León. Manuscrito; 1 folio; Castellano; R (incompleto)

147. ADME/BA-CONVENTO-1128-35971

1799,abril,18/1802,febrero,19.Madrid-Berlanga-Llerena

Secularización perpetua de José Antonio Álvarez del convento de San Sebastián de Llerena. Manuscrito; 42 folios; Castellano y Latín; Buena

148. ADME/BA-CONVENTO-1128-35971bis

1800,noviembre,11.Madrid-Llerena

Venta de tierras del convento suprimido de Santo Domingo de Llerena.

Manuscrito; 2 folios; Castellano; R (incompleto)

149. ADME/BA-CONVENTO-1128-35979bis

1821,mayo,10.Llerena/1821,mayo,23.Madrid

Salida de la clausura del convento de Santa Isabel de Llerena. Manuscrito; 1 folio; Castellano; Buena

150. ADME/BA-CONVENTO-1128-35979bis

1832,julio,13.Madrid-Llerena

Pleito en el que participa el convento de Sebastián de Llerena. Manuscrito; 4 folios; Castellano; R (incompleto)

151. ADME/BA-CONVENTO-1128-35980

1720,julio,20/1720,septiembre,20.Llerena-Madrid

Abandono de la clausura de una religiosa del convento de Santa Clara de Llerena. Manuscrito; 19 folios; Castellano; Buena

152. ADME/BA-CONVENTO-1146-36495n 2

1815,diciembre,7/1816,(sm),21.Madrid-Mérida

Petición de religiosas para seguir habitando el convento de la Concepción de Mérida. Manuscrito; 8 folios; Castellano; Buena

153. ADME/BA-CONVENTO-1146-(16)

1822, enero,2.Madrid/1822,febrero,23.Llerena-Mérida

Secularización perpetua de Josefa Salguero del convento de Santa Clara de Mérida. Manuscrito; 8 folios; Castellano y Latín; Buena

154. ADME/BA-CONVENTO-1146-(23)

1801,abril,25.Madrid/1801,mayo,5.Llerena-Mérida

Renuncia de una religiosa, a su estado, en el convento de Santa Clara de Llerena. Manuscrito; 1 folio; Castellano; Buena 
155. ADME/BA-CONVENTO-1146-(24)

1821,mayo,4.Mérida/1821,noviembre,23.Llerena-Madrid

Secularización perpetua de Isabel María González del convento de Santa Clara de Mérida. Manuscrito; 9 folios; Castellano y Latín; Buena

156. ADME/BA-CONVENTO-1146-(25)

1822,enero,2.Madrid/1822,febrero,23.Llerena-Mérida

Secularización perpetua de Antonia Vallejo del convento de Santa Clara de Mérida. Manuscrito; 8 folios; Castellano; Buena

157. ADME/BA-CONVENTO-1183-(2)

1798,junio,11.Madrid/1798,junio,26.Llerena-Bienvenida

Secularización perpetua de María del Carmen Pardillo religiosa del convento de la Concepción de Bienvenida. Manuscrito; 5 folios; Castellano y Latín; R (manchas de humedad)

158. ADME/BA-CONVENTO-1175-37439

1801,noviembre,16.Madrid-Llerena

Salida de la clausura de Jacinta Durana del convento de Santa Isabel de Llerena. Manuscrito; 6 folios; Castellano; Buena

159. ADME/BA-CONVENTO-1172-37256

1821,marzo,11.Mérida/1848,agosto,31.Llerena-Madrid

Secularización perpetua de Diego Muñoz del convento de San Francisco de Mérida. Manuscrito; 19 folios; Castellano y Latín; R (mal cosido)

160. ADME/BA-CONVENTO-1287-42978

1593, diciembre, 1.Madrid/1594,marzo,13.Llerena

Entrada de nuevos religiosos en los conventos franciscanos de Llerena.

Manuscrito; 11 folios; L. Bastarda; Buena

161.ADME/BA-CONVENTO-1380-45986

1677, noviembre,13.Madrid/1677,noviembre,27. Guadalcanal-Llerena

Traslado de religiosas al convento de Santa Ana de Llerena. Manuscrito; 5 folios;

L. Procesal; R (manchas)

162. ADME/BA-CONVENTO-1408-48486

1803,septiembre,19/1805,noviembre,6.Llerena-Madrid

Patronazgo del convento de Santa Ana de Llerena. Manuscrito; 17 folios; Castellano; Buena

163. ADME/BA-CONVENTO-1435-50766

1821,noviembre,13/1847,julio, 12.Llerena-Madrid-(Badajoz)

Secularización perpetua de Manuel de la Vera en el convento de San Gabriel de Badajoz. Manuscrito; 7 folios; Castellano y Latín; Buena

164. ADME/BA-CONVENTO-44-1219

1858,enero,18.Jerez de los Caballeros/1862,agosto,2.Badajoz-Madrid

Reparación del convento de Nuestra Señora de Gracia de Jerez de los Caballeros. Manuscrito; 13 folios y 4 cuartillas; Castellano; Buena

165. ADME/BA-CONVENTO-27-670

(sd).(Fregenal de la Sierra)/1777,noviembre,1.Badajoz-Madrid

Pensión por asistencia a un religioso de la Compañía de Jesús de Fregenal de la

Sierra. Manuscrito; 10 folios y 1 cuartilla; Castellano; buena 
166. ADME/BA-CONVENTO-28-715

1826,agosto,8.Madrid/1827,marzo,9.Badajoz-Fregenal de la Sierra

Entrada de una doncella en el convento de Santa Clara de Fregenal de la Sierra. Manuscrito; 11 folios; Castellano y Latín; Buena

167. ADME/BA-CONVENTO-29-756

1852,julio,20.Fregenal de la Sierra/1853,abril,5.Badajoz-Madrid

Traslado de la religiosa Josefa Armijo del convento de Santa Clara al de la Paz en Fregenal de la Sierra. Manuscrito; 10 folios y 2 cuartillas; Castellano y Latín; Buena

168. ADME/BA-CONVENTO-29-762n ${ }^{\circ} 1$

1858,diciembre,8.Fregenal de la Sierra/1859,noviembre,15.Badajoz-Madrid

Reparación del convento de la Paz de Fregenal de la Sierra.

Manuscrito; 5 folios y 2 cuartillas; Castellano; Buena

169. ADME/BA-CONVENTO-64-1592n 22

1772,octubre,31.Madrid- (Talavera la Real)-(Jaén)

Carta de privilegio, por la que su majestad el rey Carlos II concede al convento de Carmelitas Descalzas de Talavera la Real 15300 maravedíes de un juro en Jaén. Manuscrito; 7 folios; Castellano; Buena

170. ADME/BA-CONVENTO-42-1172

1820,diciembre,10.Madrid/1820,diciembre,22.Badajoz-Jerez de los Caballeros

Salida de la clausura de la religiosa María de la Concepción Jara del convento de la Esperanza de Jerez de los Caballeros.

Manuscrito; 10 folios y 1 cuartilla; Castellano y Latín; Buena

171. ADME/BA-CONVENTO-42-1173bis

1821,mayo,10/1821,octubre,26.Badajoz-Jerez de los Caballeros-Madrid

Secularización perpetua de la religiosa Brígida Quevedo del convento Madre de Dios de Jerez de los Caballeros. Manuscrito; 4 folios; Castellano y Latín; Buena

172. ADME/BA-CONVENTO-42-1173bis

1821,mayo,6/1821,octubre,26.Badajoz-Madrid-Jerez de los Caballeros

Secularización perpetua de la religiosa María de la Concepción Quevedo del convento Madre de Dios de Jerez de los Caballeros. Manuscrito; 4 folios; Castellano y Latín; Buena

173. ADME/BA-CONVENTO-42-1174n²

1821,mayo,24/1821,agosto,8.Jerez de los Caballeros-Madrid-Oliva de la Frontera

Conservación de la iglesia del convento suprimido de San Agustín de Jerez de los Caballeros. Manuscrito; 8 folios y 2 cuartillas; Castellano; Buena

174. ADME/BA-CONVENTO-42-1175n'1

1821,abril,3/1821,noviembre,9.Badajoz-Madrid-Jerez de los Caballeros

Secularización perpetua María Dolores Núñez del convento de Gracia de

Jerez de los Caballeros. Manuscrito; 5 folios; Castellano y Latín; Buena

175. ADME/BA-CONVENTO-42-1175n'2

1821,enero,6/1821,diciembre,31.Badajoz-Madrid-Jerez de los Caballeros

Secularización perpetua de Ana Soto del convento de la Luz de Jerez de los

Caballeros. Manuscrito; 3 folios y 1 cuartilla; Castellano y Latín; Buena 


\section{ADME/BA-CONVENTO-42-1175n 3}

1821,noviembre,6/1821,diciembre,23.Badajoz-Jerez de los Caballeros-Madrid Secularización perpetua de Josefa López Triviño del convento de la Luz de Jerez de los Caballeros. Manuscrito; 3 folios y 1 cuartilla; Castellano y Latín; Buena

177. ADME/BA-CONVENTO-42-1175n 4

1821,mayo,11/1821,octubre,26.Badajoz-Jerez de los Caballeros-Madrid

Secularización perpetua de Marciana Coba del convento de Madre de Dios de Jerez de los Caballeros. Manuscrito; 4 folios; Castellano y Latín; Buena

178. ADME/BA-CONVENTO-42-1175n 5

1821,enero,6.Jerez de los Caballeros/1821,diciembre,23.Badajoz-Madrid

Secularización perpetua de Vicenta Triviño del convento de la Luz de Jerez de los Caballeros. Manuscrito; 3 folios y 1 cuartilla; Castellano y Latín; Buena

179. ADME/BA-CONVENTO-42-1175n 6

1821,marzo,12/1821,diciembre,21.Badajoz-Madrid-Jerez de los Caballeros

Secularización perpetua de la religiosa María Paurano del convento de la Esperanza de Jerez de los Caballeros. Manuscrito; 4 folios; Castellano y Latín; Buena

180. ADME/BA-CONVENTO-42-1176n ${ }^{\circ} 1$

1821,junio,23/1821,septiembre,22. Badajoz-Jerez de los Caballeros-Madrid

Secularización perpetua del religioso Francisco Rodríguez del convento de Santa Margarita de Jerez de los Caballeros. Manuscrito; 4 folios; Castellano y Latín; Buena

181. ADME/BA-CONVENTO-42-1176n 2

1821,mayo,27/1821,agosto,21. Badajoz-Jerez de los Caballeros-Madrid

Secularización perpetua del religioso José Jara del convento de San Agustín de Jerez de los Caballeros. Manuscrito; 5 folios; Castellano y Latín; Buena

182. ADME/BA-CONVENTO-42-1176n 3

1821,mayo,28/1821,octubre,17. Badajoz-Jerez de los Caballeros-Madrid

Secularización perpetua del religioso Antonio Aballe del convento de San Agustín de Jerez de los Caballeros. Manuscrito; 4 folios; Castellano y Latín; Buena

183. ADME/BA-CONVENTO-42-1176n 4

1821,junio,26/1821,septiembre,10. Badajoz-Jerez de los Caballeros-Madrid

Secularización perpetua del religioso Pedro Jurado de San Agustín de Jerez de los Caballeros. Manuscrito; 5 folios; Castellano y Latín; Buena

184. ADME/BA-CONVENTO-42-1176n ${ }^{\circ} 5$

1821,marzo,13/1821,agosto,30. Badajoz-Jerez de los Caballeros-Madrid

Secularización perpetua del religioso Alonso Berlanga del convento de Santa Margarita de Jerez de los Caballeros. Manuscrito; 5 folios; Castellano y Latín; Buena

185. ADME/BA-CONVENTO-42-1178n ${ }^{\circ} 1$

1821,marzo,2/1821,abril,5.Badajoz-Jerez de los Caballeros-Madrid

Secularización perpetua de la religiosa Mónica Meléndez del convento de la Consolación de Jerez de los Caballeros. Manuscrito; 4 folios; Castellano y Latín; Buena

186. ADME/BA-CONVENTO-42-1178n 2

1821,mayo,17/1822,septiembre,14. Badajoz-Jerez de los Caballeros-Madrid

Secularización perpetua de la religiosa María Pilar Conejo del convento de Madre de Dios de Jerez de los Caballeros. Manuscrito; 5 folios; Castellano y Latín; Buena 
187. ADME/BA-CONVENTO-42-1178n 3

1821,abril,10/1822,agosto,2.Badajoz-Jerez de los Caballeros-Madrid

Secularización perpetua de María Jara del convento de la Luz de Jerez de los Caballeros. Manuscrito; 4 folios; Castellano y Latín; Buena

188. ADME/BA-CONVENTO-42-1178n ${ }^{\circ}$

1821,mayo,16/1822,mayo,7.Badajoz-Jerez de los Caballeros-Madrid

Secularización perpetua de Inés de Trepo del convento de Gracia de Jerez de los Caballeros. Manuscrito; 5 folios; Castellano y Latín; Buena

189. ADME/BA-CONVENTO-42-1178n 5

1822,enero,30/1822,marzo,25.Badajoz-Jerez de los Caballeros-Madrid

Secularización perpetua de la religiosa Inés Pallejo del convento de la Consolación de Jerez de los Caballeros. Manuscrito; 4 folios; Castellano y Latín; Buena

\section{REFERENCIAS BIBLIOGRÁFICAS}

ALDEA VAQUERO, Q.; MARÍN MARTÍNEZ, T.; VIVES GATELL, J. (1972-1987). Diccionario de Historia Eclesiástica de España. Madrid, Instituto Enrique Florez.

ASOCIACIÓN DE ARCHIVEROS DE LA IGLESIA (2000). "Aportación del director del Archivo Diocesano don Eladio Menéndez Venegas". Guía de los Archivos de la Iglesia en España, 2000, p. 37 y ss.

LÓPEZ LÓPEZ, T. (2000). "La diócesis de Badajoz: Historia ya conclusa". Separatas del boletín de la Real Academia de Extremadura de las Letras y las Artes.

MONTES, J. J. (2002). "Entrevista con don Eladio Méndez Venegas, Archivero Diocesano". Revista Iglesia en Camino, $\mathrm{n}^{\mathrm{a}} 459$, contraportada.

SARMIENTO PÉREZ, J. (2005). Reforma beneficial en la Diócesis de Badajoz durante la crisis del Antiguo Régimen (1769-1841). Badajoz, Diputación Provincial.

SOLANO DE FIGUEROA, J. (1929-1932). Historia eclesiástica de la ciudad y obispado de Badajoz. Badajoz.

SOLAR Y TABOADA, A. (1945). Historia eclesiástica de la ciudad y obispado de Badajoz, continuación de la escrita por Juan Solano de Figueroa. Badajoz.

SUÁREZ DE FIGUEROA, D. (1976). Historia de la Ciudad de Badajoz. Badajoz. 